\title{
Caregivers' Feeding Experiences and Support of Their Child with Cerebral Palsy
}

\author{
Christine Taylor $\mathbb{D}^{1} \cdot$ Ariana C. Kong $^{2} \cdot$ Jann Foster $^{1} \cdot$ Nadia Badawi $^{3,4} \cdot$ Iona Novak $^{3}$
}

Accepted: 24 September 2021 / Published online: 4 October 2021

(c) The Author(s), under exclusive licence to Springer Science+Business Media, LLC, part of Springer Nature 2021

\begin{abstract}
Feeding difficulties are often reported in children with cerebral palsy (CP) and are associated with caregiver stress. This study explored the feeding experiences and support of caregivers with children who have CP. A qualitative approach was used where semi-structured telephone interviews were conducted and audio recorded. Thematic analysis was used to code and analyse the transcribed interview data from the eleven mothers that participated. Four major themes were identified from the data: Child-centred world, Making decisions, Knowing their child, and Seeking and receiving support. Caregivers knew their child's unique needs and made daily decisions around feeding based upon the child's feedback and changing condition. Family support was viewed as important, although the caregivers still reported feeling stressed. Health professional support varied from "amazing" to "frustrating", which contributed to the caregivers' stress. However, no single support strategy was appropriate as their needs or preferences varied. It is recommended that health professionals take an individualised partnership approach with caregivers and their child, with particular attention to those caregivers who lack a friend or family support and those who are physically isolated.
\end{abstract}

Keywords Feeding $\cdot$ Cerebral palsy $\cdot$ Experiences $\cdot$ Caregivers $\cdot$ Support

\section{Highlights}

- Provides insight into caregivers' experiences in managing feeding difficulties of their child with cerebral palsy.

- Major themes were: child-centred world, making decisions, knowing their child, and seeking and receiving support.

- Caregivers experienced stress in many aspects of their child's feeding difficulties.

- Health professional support should be individualised, reasonable, and timely.

- A variety of support strategies should be used to meet the different needs and preferences of caregivers.

Christine Taylor

ch.taylor@westernsydney.edu.au

1 School of Nursing and Midwifery, Western Sydney University, Building EB.LG, Parramatta South Campus, Locked Bag 1797, Penrith, NSW 2751, Australia

2 Centre for Oral Health Outcomes \& Research Translation (COHORT), School of Nursing \& Midwifery, Western Sydney University, South-Western Sydney Local Health District, Ingham Institute Applied Medical Research, Level 3, Ingham Institute, Locked Bag 7103, Liverpool BC NSW 1871, Australia

3 Cerebral Palsy Alliance Research Institute, Brain Mind Centre, The University of Sydney, Westmead campus, Hawkesbury Road, Westmead, NSW 2145, Australia

4 The Grace Centre for Newborn Intensive Care, The Children's Hospital at Westmead, Corner Hawkesbury Road and Hainsworth Street, Locked Bag 4001, Westmead, NSW 2145, Australia
Feeding problems are common in children with cerebral palsy (Andrew et al., 2012; Arvedson, 2013), with studies reporting between 21 to $58 \%$ of children with $\mathrm{CP}$ having some level of feeding difficulty (Benfer et al., 2016; Dahlseng et al., 2012; Erkin et al., 2010; Fung et al., 2002). Feeding children with CP may include the breast, bottle, tube, and/or oral routes. Cerebral palsy (CP) is the most common cause of motor disability among children in early childhood (Michael-Asalu et al., 2019; Oskoui et al., 2013). $\mathrm{CP}$ is an umbrella term for a condition that affects movement and posture, however, the extent of impairment varies between children, and musculoskeletal function may deteriorate over time (Motion et al., 2002; Rosenbaum, 2014).

Motor dysfunction in CP often affects the muscles of swallowing and chewing, leading to dysphagia and feeding difficulties, such as impaired sucking from a teat or drinking 
from a cup (Benfer et al., 2014; Calis et al., 2008; Dahlseng et al., 2012; Odding et al., 2006). This can result in children vomiting, 'gagging', drooling excessively, or aspirating feed, and children with severe motor impairment are the most affected (Benfer et al., 2016; Erkin et al., 2010; Fung et al., 2002; Motion et al., 2002). Children with these impairments have a high morbidity, usually from respiratory problems caused by repeated food or fluid aspirations (Blackmore et al., 2018; Boel et al., 2019). In a study by Sullivan et al. (2000), over half of the parents reported their child with CP regularly choked during feeding. Severe motor impairment can also lead to the need for surgical insertion of a gastrostomy tube to bypass the oropharynx (Benfer et al., 2016; Dahlseng et al., 2012; Erkin et al., 2010; Fung et al., 2002) to allow direct feeding into the stomach, thus avoiding aspiration into the lungs (Gantasala et al., 2013). The ability to feed oneself or to sit in an upright position unaided, regardless of age, can also be affected by CP (Andrew et al., 2012), so these children require continued assistance from caregivers for feeding (Benfer et al., 2014; Dahlseng et al., 2012). These feeding difficulties can contribute to undernutrition in children with $\mathrm{CP}$, affecting growth (weight and height), and can lead to poor general health and increased risk for infections (Andrew et al., 2012; Dahlseng et al., 2012; Fung et al., 2002; Reyes et al., 2019).

Feeding difficulties and mealtimes are recognised as being stressful for caregivers of children with CP (Andrew et al., 2012; Parkes et al., 2011; Smith et al., 1999; Sullivan et al., 2000). Caregiver concerns related to child feeding have included fear of their child choking whilst feeding due to impaired or hyperactive gag reflex and uncoordinated swallowing (Sullivan et al., 2000, 2004); prolonged time taken to prepare the food and feed the child, which can take three hours or more per day (Sullivan et al., 2000; Morrow et al., 2008); concerns about the child's nutritional status and health as many caregivers considered their child underweight (Sullivan et al., 2000, 2004); financial costs associated with feeding (Mobarak et al., 2000), and lack of enjoyment in feeding their child (Sullivan et al., 2000).

The presence of social support, such as family and friends, may be an effective buffer to mitigate stress in this population (Pousada et al., 2013; Pfeifer et al., 2014). Caregivers' who felt they were adequately supported have reported less caregiver burden (Carona et al., 2013) and greater well-being (Skok et al., 2006) than those who felt less supported. An important source of support is the caregiver's 'significant other' as well as family and friends (Al-gamal \& Long, 2013; Wang et al., 2020). However, the personal day to day feeding experiences of caregivers of children with $\mathrm{CP}$ has not been extensively addressed in the literature, particularly in children with different motor severities and feeding difficulties. Sleigh
(2005) and Peterson et al. (2006) both found that caregivers of children with gastrostomy tubes expressed a loss of nurturing and close contact with the child, restriction of social activities, and distress at being unable to provide oral food. Sleigh also identified some experiences of mothers whose child is orally fed, such as constant pressure by health professionals to get calories into their child and their views not being heard. Support was not specifically explored in either study.

Support for caregivers around feeding their child with CP needs further exploration for both oral-fed and tube-fed children. Without understanding the personal impact feeding difficulties have on caregivers, then health professionals, early interventionists and educators cannot identify appropriate and timely support interventions for these families. Thus, the aim of this study was to explore the experiences and viewpoints on support of caregivers around feeding their child with $\mathrm{CP}$, with the research question 'What are caregivers feeding and support the experiences of their child with cerebral palsy?'.

\section{Methods}

A qualitative descriptive approach was used for this study, as the approach is used when wishing to accurately reflect the participants' views or comments within a naturalistic setting free of pre-conceived theoretical commitments (Bradshaw et al., 2017; Sandelowski, 2000). Researchers using this approach "stay close to their data and to the surface of words and events" (Sandelowski, 2000, p. 334). The study was conducted using in-depth interviews with caregivers. Interviews focused on exploring the rich, unique histories and experiences of the participants (Merriam \& Tisdell, 2016) to obtain insight into their feeding and support experiences with their child with $\mathrm{CP}$. The research group was multidisciplinary with a strong interest in feeding management and/or cerebral palsy. The team consisted of nurse academics, a neonatologist, a director of research (allied health professional) and research assistants in nursing and allied health. The researchers all had experience in research methods and implementation, with the interviewers having previous experience with interviewing, and all were female.

\section{Participant Recruitment}

Caregivers eligible for an interview had a child with $\mathrm{CP}$ under the age of 18 years and resided in Australia. Purposive sampling was used to recruit participants by an invitation to participate posted on an Australian non-for-profit organisation's website (providing support services to carers and people with $\mathrm{CP}$ ), their Facebook social page and 
biannual newsletter, and included the research team's contact details. Potential participants who contacted the team were provided with a Participant Information Sheet.

The interviews were part of a larger study exploring the feeding difficulties and support of caregivers of children with $\mathrm{CP}$ and included an anonymous online survey emailed to registrants on the CP population register in New South Wales and the Australian Capital Territory. At the end of the survey was an invitation to potential participants for an interview and they could leave contact details for the researchers to contact them. Our exploration of the interview data is presented in this paper.

\section{Data Collection}

Telephone interviews were conducted so that location and transportation did not preclude participation. All interviews were conducted by three researchers (CT, AS, ACK), although only one or two were present during each interview. The interviews were conducted from February 2017 to November 2017 using an interview guide comprising of several questions and prompts to identify key demographic data for caregivers and their child and open questions related to their experiences around feeding and feeding support. Reflexive memos were written simultaneously by the researchers when conducting the telephone interviews. All interviews were audio recorded and transcribed by a professional transcription service. Examples of the questions included:

What is your relationship to the child with CP?

What are your experiences in feeding your child (with $\mathrm{CP}$ )?

What feeding support helped you (in hospital and at home)?

\section{Data Analysis}

The interview transcripts were checked separately for accuracy by two researchers (CT, ACK) to enhance rigor. Maintaining a reflexive journal for thoughts during the analysis was undertaken for auditability to keep a record of decisions made around coding and themes (Liamputtong, 2020). Braun et al.'s reflexive thematic analysis (2019) was used to guide the analysis. After several readings of the transcripts to familiarise themselves with the data, initial codes were generated inductively, then themes were constructed from the codes based on similarity of meaning. Initial themes were revised and refined to generate overarching themes (based on broader patterns of meaning), sub-themes and minor themes. Coding was initially undertaken by two researchers separately (CT, ACK) and then all research team members reviewed the generated codes, and then later reviewed the themes and sub-themes, regarding the plausibility of the coding and revised themes. This enhanced credibility and dependability as the data were checked to see if the coding and themes were consistent with the data over time by researchers who were not involved in the interview process (Merriam \& Tisdell, 2016). The themes were coded manually and entered in the qualitative software program NVivo version 12 (QSR International Pty Ltd, 2018) to assist sorting and analysis.

\section{Results}

\section{Participant Details}

Pseudonyms were assigned for all participants and children prior to the analyses, including names of other people and places. All participants were interviewed via telephone in their own home and interviews varied in length from 24 to $61 \mathrm{~min}$ (mean $=40 \mathrm{~min}, S D=10.2$ ).

Thirteen caregivers volunteered, however two caregivers had children aged 18 years and over so were not included in the study. This left 11 caregivers whose interview data were analysed. All caregivers were mothers of a child with CP and all were married and living with the father, except Natalie, who was separated from her husband. The average age of the caregivers was 40.5 years $(S D=4.9)$ (Table 1). Most of the caregivers lived in large cities $(n=8)$ : two lived in large regional towns and one caregiver resided in a rural area. Most of the caregivers identified their ethnicity as Australian $(n=8)$, had a least one other child $(n=8)$, and did not work in paid employment $(n=6)$.

The children's average age was 5 years $(S D=4.1$ years) (Table 2), with six of the 11 children aged under 5 years; six were boys. Most of the caregivers $(n=8)$ identified their child's CP type: five had quadriplegia, one hemiplegia, and one ataxia. Motor function in the children varied, with seven caregivers identifying their children's Gross Motor Function Classification System (GMFCS) level that ranged from I (mildest form) to V (most severe). The GMFCS is based on the child's mobility independence and whether they need assistance, such as a wheelchair (Palisano et al., 1997). Most of the children were fed orally; three of the children were fed via a gastrostomy (GT) tube and one had a nasogastric (NG) tube for water only (Table 2). 
Table 1 Participant details (*Pseudonyms Used)

\begin{tabular}{|c|c|c|c|c|c|}
\hline Participant* & $\begin{array}{l}\text { Age } \\
\text { (years) }\end{array}$ & Ethnicity $^{\mathrm{a}}$ & Residence & $\begin{array}{l}\text { Hours } \\
\text { worked /week }\end{array}$ & $\begin{array}{l}\text { Number of other } \\
\text { children }\end{array}$ \\
\hline Amanda & 47 & Australian & City & 34 & 1 \\
\hline Carol & 37 & Australian & Regional City & Nil & 3 \\
\hline Debbie & 47 & Australian & City & Nil & 1 \\
\hline Dianna & 39 & North American & City & Nil & 2 \\
\hline Jessica & 34 & $\begin{array}{l}\text { Macedonian/ } \\
\text { Serbian }\end{array}$ & City & Nil & 4 \\
\hline Kylie & 43 & Anglo-Australian & $\begin{array}{l}\text { Greater } \\
\text { metropolitan area }\end{array}$ & Nil & Nil \\
\hline Lily & 40 & $\begin{array}{l}\text { Chinese- } \\
\text { Australian }\end{array}$ & City & 10.5 & Nil \\
\hline Natalie & 41 & South American & Rural & 10 & 1 \\
\hline Penny & 36 & Australian & City & Nil & Nil \\
\hline Suzanne & 46 & Australian & City & 37 & 1 \\
\hline Tracey & 34 & Australian & City & 16 & 1 \\
\hline
\end{tabular}

${ }^{a}$ Ethnicity—as identified by participant

Table 2 Child details (*pseudonyms used)

\begin{tabular}{lllllll}
\hline Participant $^{*}$ & Child's name* $^{*}$ & Child's Gender & Child's Age & Feeding & Child's CP type & GMFCS $^{\text {a where stated }}$ \\
\hline Amanda & Ben & M & 8 years & Oral & Hypotonic quadriplegia & II-III \\
Carol & Jake & M & 21 months & Oral/bottle & Ataxic & Not identified \\
Debbie & Eliza & F & 13 years & Oral & Ataxic & Not identified \\
Dianna & Emily & F & 3 years & PEG & Spastic quadriplegia & IV-V* \\
Jessica & Aiden & M & 15 months & Oral purees & Mild form & Not identified \\
Kylie & Luke & M & 2 years & PEG/oral & "Systemic" & V* \\
Lily & Peter & M & 4 years & PEG & Dystonic spastic quadriplegia & V \\
Natalie & Isabella & F & 6 years & Oral - soft & Unknown & I-II \\
Penny & Jared & M & 2.5 years & oral & Spastic quadriplegia & IV \\
Suzanne & Charlotte & F & 12 months & NG water only, oral & Dystonic spastic quadriplegia & Not identified \\
Tracey & Kara & F & 5 years & oral & Right-sided hemiplegia & III*
\end{tabular}

${ }^{\mathrm{a}}$ GMFS Gross Motor Function Classification System

\section{Thematic Analysis}

Four major themes were identified (Table 3): 'Child-centred world'; 'Making decisions'; 'Knowing their child'; and 'Seeking and receiving support'. The caregivers also identified difficulties around feeding and support in all themes. Sub-themes are also listed in Table 3 and all themes are described below.

\section{Theme 1: Child-Centred World}

Activities around feeding took up a large part of these caregivers' days and were a major focus of their lives. This was clearly articulated by Jessica: "I spend so much time with Aiden's needs because he needs that...it's like Aiden is the centre of our home". Many caregivers had goals to improve their child's feeding skills and spent time and effort in developing these skills. The caregivers recognised the importance of feeding for the child's health and development. Subthemes were 'Concern for child', with its own minor theme of "Worries and stress', and 'Time', with its own minor theme of 'Building capacity'.

'Concern for the child' was central to the caregivers' care and motivated the caregivers' in being vigilant over their child's health, safety, growth, and well-being. For example, caregivers were concerned about their child choking or aspirating due to their feeding difficulties and this led to worries about the child's safety during feeding. "That's what the risk we're taking ... because we're so terrified of her choking because she does not get to chew things" (Tracey). Another important concern was around their child's weight and not obtaining enough calories or nutrients for their growth. Amanda, whose child is fed orally, stated, "I' $m$ always on a mission to get as many calories 
into him as I can". Caregivers were inventive and used techniques specific for their child to avoid them choking, such as feeding slowly, cutting food in small pieces, thickening fluids, observing the food was swallowed, and upright positioning.

The difficulties some caregivers had in feeding their child was a source of 'Worries and stress'. Tracey stated "there are times where I just lose it and I get so stressed trying to feed her... I actually find that very upsetting and stressful most days". This stress was compounded when pressure was placed on caregivers by health professionals and service providers to increase the child's weight, even though caregivers were trying their best to achieve weight gain. For example, Carol stated:

[sigh] Before we were linked in with [CP service] ..., I was in tears pretty much every day at mealtime. Extremely stressed. I had constant pressure on me every - I had weekly weigh-ins at the hospital to measure his weight gain and I had constant pressure on me to be getting a certain amount of food and fluids into him because of his weight problems.

Trying to get the child to eat was also stressful: "But it's just really, really stressful for the whole family. What's normally sit down for a family meal we know you're going to be in for a fight because if she just doesn't want to eat" (Debbie). Although most caregivers expressed worries and stress around feeding their child, they also showed resilience and the ability to cope with the challenges around their child's feeding difficulties. Some strategies that helped caregivers cope included, feeling well-supported, keeping to a strict routine, and not dwelling on problems. "Oh yeah I'm fine. I go to the gym to manage my stress" (Jessica).

'Time' was a major aspect of the caregiver's world, regardless of whether the child was feeding orally or via a gastrostomy tube. Children who were fed via a gastrostomy tube often needed frequent feeds and medications administered. Lily stated: "One feed takes an hour and $15 \mathrm{~min}$. We do five of those a day. We start at 5:00am in the morning, ... Our last feed finishes at 11:00 pm. So they're long days". Caregivers whose children were fed orally described the child's slowness in feeding due to difficulties such as chewing, swallowing and the amount tolerated, so this meant meals took longer to complete. For example, Suzanne said: "It used to take $40 \mathrm{~min}$ to an hour per feed, so three times a day with snacks". Some caregivers described feeling envious of caregivers with children without $\mathrm{CP}$ as other children could self-feed and did not require constant supervision. "So I do have those moments where I'm envious of, say, my sister who's got a child of a similar age
Table 3 Major themes, sub-themes and minor themes

\begin{tabular}{ll}
\hline Major Theme & Sub-theme \\
\hline Child-centred world & Concern for child \\
& —Worries and stress \\
& Time \\
—-Building capacity & Problem-solving \\
Making decisions & Seeking information \\
& Trial and error \\
Knowing their child & Medical and technical knowledge \\
& Unique feeding needs \\
Seeking and receiving support & Family is important \\
& Health professionals and \\
services vary & Seeking affirmation \\
& Finance-extra expenses \\
& Social networks-avoid or seek? \\
\hline
\end{tabular}

who can sit in a highchair ... she can multitask at that point" (Penny).

Not all comments were negative, however. Caregivers did express positive comments related to feeding, such as the joy they felt interacting with their child and seeing their child happy during feeding. Supervising their child gave caregivers the opportunity to spend time with the child. For example, Jessica stated: "I love sitting down and hanging out with him and ... I love like when they see that you're coming with food, they get excited".

As well as feeding the child, caregivers had to find time in their day to manage other family members, cook family meals, and attend family events or medical appointments. Caregivers were well-organised and used techniques such as such as pre-planning feeds before going out for events, preparing food to eat at the event, or pump feeding in the car. Dianna, whose child has a gastrostomy tube, stated " $I$ ' $l l$ make sure she's fed before I plan something. So, if I have a doctor's appointment or if I need to go somewhere, I'll work it around her feeds".

Caregivers also spent time 'Building capacity' of the child's feeding skills with a desire to improve and encourage development of skills and capacities essential for their future life. Jessica said: "When it comes to feeding, no. It's just really something that if it's not - I just think if it's not dealt with very early on, like feeding and stuff, it affects their whole life". Caregivers sought a balance between optimally developing their child's feeding skills versus wanting the mealtimes to be pleasurable for their child. Carol said: "It was also just giving him the foods that he actually liked, rather than trying to make him have different varieties ... just getting him eating first and then moving on to something better". 


\section{Theme 2: Making Decisions}

Caregivers were faced with making daily feeding decisions and solving feeding problems as the child's needs or behaviours changed. Often this involved a process of trial and error as well as seeking information or advice from a variety of sources, such as health professionals and social groups. Sub-themes included 'Problem-solving', 'Seeking information', and 'Trial and error'.

Caregivers had to employ 'Problem solving' abilities and showed inventiveness, creativity, and flexibility to adapt quickly to the changing needs of their child. Partners were often involved in the daily decisions around feeding and some caregivers telephoned their partners at work to discuss feeding issues and decisions. Changing needs of the child included feeding abilities or behaviours, food preferences, or child illness. Lily, whose child is fed via gastrostomy tube, stated:

It changes all the time, because if he is sick, then we have to change it [the feed] to then suit him. So sometimes we've moved to continuous feed for $24 \mathrm{~h}$ when he's sick. ... if he's got something like a gastro bug then we're doing slow feeds of fluids and it could just be water or it could be electrolytes.

The caregivers were also cautious when making changes to their child's diet or feeding routine, such as changing pump rates or trying new foods or textures. Lily stated: "but we've been a bit reluctant to do that [change the pump rate] because we've just thought, oh this seems to work, let's not push the boundaries".

'Seeking information' and advice from a variety of sources helped inform the caregivers' daily decision making. Sources included their innate 'common' knowledge and experience, health professionals, the internet, and social networks. For example, Tracey said, "A lot of it has just been self-taught, just for my husband and I - just learning ourselves". Some caregivers found health professionals and services provided useful advice, such as suggesting different foods, how to increase weight, seating position, and chewing and swallowing skills. Amanda stated, "the speech pathologist just had some great tips... he had these little biscuits that were a bit harder, just to get that movement of his tongue and things like that".

In making decisions around what was best for their child, sometimes caregivers ignored health professional advice for a variety of reasons, such as the health professional's lack of knowledge, lack of information they were able to provide about relevant support services, or recommendations that were not considered feasible or appropriate by the caregiver. Dianna said, "Look, they were never able to give me a straight answer", and Jessica stated that her GP (family medical practitioner) "He didn't know much but he sort of directed me. But that's the thing, he didn't know much". Lily, whose child is fed via a gastrostomy tube, stated: "They said, oh you shouldn't really feed in the car, but that was just going to make life too impossible if we didn' $t$ ".

Some caregivers found social networks useful for information such as recipes, whilst other caregivers did not rely on them. Penny said: "I would definitely go down the Facebook avenue if I had a question and am looking for an answer". Regardless of their information source, caregivers were discerning in their use of information, wanting credible yet relevant information to help inform their decisions. Jessica said: "I'd rather just hear it from a professional. You know how people say oh Dr Google, like that's why I just don't, because you don't know if you're getting the right advice or not".

'Trial and error' was often used by caregivers to identify which foods and feeding techniques best suited their child's unique needs, showing flexibility in managing feeding and food choices. For example, Debbie, whose child had very limited dietary range of foods, stated: "We've tried all the feeding methods. We've tried disguising, we've tried bribing. We've had picnics. We've had psychologists in to try and she just will not eat other types of food. ... we have tried everything under the sun". Importantly, children were part of the decision-making process as caregivers relied on feedback from the child's behaviour, such as responses to feeding, to determine the success of feeding or decide if changes needed to be made to the food or technique. "Children are very good guides, and they'll tell you what they sense and can't do" (Jessica).

\section{Theme 3: Knowing Their Child}

The caregivers developed feeding expertise in 'Knowing their child' through interactions and experiences with their child. Each child had individual feeding difficulties or needs unique to them, and caregivers developed expertise and knowledge in managing their child with CP. Sub-themes include 'Medical and technical knowledge' and 'Unique feeding needs'.

Caregivers demonstrated 'Medical and technical knowledge' in using medical terminology when discussing their child's various interventions and tests to the interviewer and understanding how the child's medical condition contributed to their feeding difficulties. One caregiver, Kylie, expressed the view, "It's like anything to do with a special needs child; a parent or a carer has to know so much more". Debbie, whose child self-feeds, stated: "Because she has a tremor, I have to make sure it's easy for her, for the spoon or the fork to then coordinate it into her mouth. She misses her mouth quite a bit [laughs]". For caregivers with children who had gastrostomy feeds (Dianna, Kylie, and 
Lily), they showed expertise and knowledge in technical aspects of their child's care, such as managing feeding pumps and gastrostomy tubes, and were a source of knowledge for other carers who relied upon the caregivers to troubleshoot pump problems. For example, Lily stated: "I' $m$ at work so sometimes I can usually talk them [School] day care staff] through [the problem]. If they say, 'the pump's just given us this error message and we' re not quite sure",.

Each child had 'Unique feeding needs' and differed in eating skills, food tolerances, or liked and disliked different foods, which also changed across time. Children's eating difficulties included food refusal, gagging, vomiting, chewing, poor sucking, lack of appetite or interest, and difficulty holding forks and spoons. Caregivers showed creativity and flexibility in using different food preparation techniques to suit their child, for example, separating textures, chopping and mashing foods, and having no 'lumps'. For example, Carol stated: "At first, I had to sort of mash it a bit, or soften it, like steam it so it's a bit softer for him to begin with". Even the way food is introduced into the mouth requires skill and thought by the caregivers, as Jessica stated: "When we feed, we've got scrape it [food] on the top of his mouth and then he swallows it".

\section{Theme 4: Seeking and Receiving Support}

Support was discussed by all caregivers, however, the sources and helpfulness of the support varied. Without support some caregivers felt isolated and despondent. Barriers and facilitators to support were also identified by the caregivers. Sub-themes were 'Family is important', 'Health professionals and services vary', 'Seeking affirmation', 'Finance-extra expense', and 'Social networks - avoid or seek?'.

All participants discussed how 'Family is important' including the positive daily support they received from partners, even though some partners could only help in the evening as they worked full time. Some caregivers relied on their family to support them to assist with feeding their child or caring for their other children. For example, Amanda stated: "Yes. My mother... I'm not sure I'd survive without her. [laugh] Currently up doing the school pickup now!'”. Not all caregivers had support from family and friends. Reasons for lack of family support included distance from family, family working full-time, or the family not understanding or having knowledge of the child's needs. Debbie stated: "So no, no family support. As I said, my friends, they' re all at different stages, and their kids didn't have the issues".

In the sub-theme 'Health professionals and services vary', caregivers' perceptions of health professionals and service support varied, ranging from being very supportive and "amazing", to being unhelpful and frustrating. Carol expressed her appreciation of the CP service she used: "So I can't fault the support that I've had from [CP service], they have been absolutely brilliant. They are the most amazing people I have ever met". Aspects caregivers found supportive from health professionals and services included treating the child as an individual, observing and giving immediate feedback on feeding technique, answering specific questions from the caregiver, and having specialist skills in feeding. Carol stated: "For starters, I think they didn't treat him as a textbook. [CP service] ...They treated him as an individual. So they looked at specifically what his needs were and where he was at and what was going on for him". Caregivers sometimes had to advocate for their child when the health professional did not consider the child's individual needs. For example, when the specialist recommended surgery for her child, Dianna responded: "I was dead set against it. I said, no, I'm not having another surgery for her just to prevent this vomiting, let's look at other options".

However, some caregivers felt unsupported by health professionals. Some reasons caregivers gave included not meeting or ignoring their specific needs and requests, not being proactive in addressing feeding difficulties, and not supporting the caregiver's choice of feeding (such as pureed diet for gastrostomy feeding). Dianna said, "I mean, look, her dietician helped me with her feeding and that sort of stuff as far as how to use the equipment ... But as far as feeding, I've really just - I didn't get that much support'.

Some caregivers had difficulty in finding the appropriate service to meet their needs: reasons included lack of knowledge by the health professional on services available, lack of information by the hospital, or lack of specific feeding specialists. Jessica said, "Well it's finding a solution that's been the challenge, and actually finding someone that understands". Debbie found the searching exhausting:

To get to this one particular specialist she was at [Xtown]. So when you've got a tired, sick baby, trying to find private people out there to help you, it was just exhausting and then we had to weigh up what's our priority.

The search to find a suitable service or health professional led some caregivers to feel frustrated or despondent at not being able to help their child. Debbie was waiting for "yet another" test to find out why her 13-year-old child was not eating, and stated: "So at the moment to be completely honest we just don't see the light at the end of the tunnel. We just feel like we're guinea pigs going round and round on a wheel".

Some barriers described by caregivers in obtaining support from health professionals and specialist services 
included distance from specialist services and busy specialists or service providers so there was a long time to wait for appointments. For example, Jessica stated: "Then to even go public, like through the hospital, you're waiting over a year or something to see someone but by then the issue's resolved itself'. Natalie, who lives in a rural area, has to travel five hours by car to a large town: "Yes, and there is not a paediatrician in [my town], ... and they have to come maybe once a month or we have to travel".

'Seeking affirmation' reflected the need by some caregivers for more personal one-on-one support for managing difficulties around feeding and affirming that the caregiver is managing their child's feeding appropriately, for example, by having someone observe what they are doing or just being present with the caregiver. Tracey stated: "I've had the speech [pathologist] coming for a little while and she said, I feel like I do nothing, and I said, but just having you here is support for me".

Caregivers commented on the 'Finance -extra expense', such as costs of equipment, specialist foods, and specialist health services. To some caregivers it was a financial burden and stopped them accessing some services, whilst other caregivers were able to manage as their partner had a wage that could support their costs. Jessica stated: "Everything I do, we've got to pay for it privately...And they [health professionals] tell you they need weekly sessions: how can you afford weekly sessions?". Debbie, who lives in a rural area, identified "There's not a lot of resources in our local area. We have to travel outside of our area to get them. Then they're usually very, very expensive as well". Some caregivers did not work as they had to care full-time for their child.

'Social networks -avoid or seek?' reflects the caregivers' different perceptions of social networks as a source of support. Social networks identified by caregivers included Facebook, friends, playgroups, and support groups. These caregivers said that the groups or websites enabled interaction and sharing of ideas and experiences, and importantly for some, a sense that they are not alone. Penny commented about her playgroup: "You sit down and you know that we' re all sort of going through similar or very different journey and understanding that sometimes you just need someone to listen to you". Kylie stated, "I didn't know anyone else in my life who was tube fed ... I felt very isolated because there was just no one else that I could bounce ideas off'. Other caregivers did not find social networks supportive, stating they were not relevant to their child's needs or that caregivers on the social sites were not in the same situation. For example, Amanda stated "Look, I'm not even in the 21st century. I'm not on Facebook. [laugh] ... I haven't ever found it necessary to seek out other people in the same situation in order to cope or to get ideas". Distance from larger groups also prevented some caregivers from joining social networks.

\section{Discussion}

This study provides insight into the feeding and support experiences of eleven caregivers around their child with CP. The caregivers' world became centred on their child with CP. They made daily decisions relating to their child's feeding and feeding problems and as such they developed expertise and knowledge in managing their child's feeding. Support for the caregivers varied, and some caregivers found health professionals supportive with advice and treatments. However, some caregivers remarked their views and the child's needs were ignored by health professionals, despite their unique knowledge of their child. This led to some caregivers ignoring health professional advice. This supports findings by Sleigh (2005) from their interviews with 10 mothers of children with $\mathrm{CP}$ and severe feeding difficulties, who also described feeling frustrated, demoralised and "not listened to" (p. 379) by health professionals. Other studies with caregivers of children with $\mathrm{CP}$, but not related to feeding, echoed their difficulties in their relationships with some health professionals (Hayles et al., 2015; Jeglinsky et al., 2012; Reid et al., 2011). Clearly, more supportive practices and interventions need to be utilised by some health professionals as these issues continues to be identified by caregivers in this study.

Some of the supportive practices of health professionals identified by caregivers in this study included listening to caregivers, giving specific timely advice to meet their child's individual needs, have specialist skills to be able to provide feedback on their feeding technique, rather than focusing on their child's weight gain. Carers of children with CP have previously identified their need to be respected, listened to, and to recognise that their child has the potential to undertake normal childhood experiences (Hayles et al., 2015), and, importantly, show respect for their child (Reid et al., 2011).

Patient and family-centred care has core concepts that involve health professionals and services working collaboratively in partnership with parents and families, including the principles of dignity and respect, information sharing and participation (Institute for Patient- and FamilyCentered Care [IPFCC], 2016). Using these principles of care has been found to optimise outcomes for parents and children (King \& Chiarello, 2014; Novak \& Berry, 2014). However, the implementation of these principles is not always fully achieved in practice, and caregivers have reported service care to be lacking in information-sharing and respectful communication (Darrah et al., 2012; McDowell et al., 2015; Molinaro et al., 2017). Families also 
differ in the importance or relevance they place on different aspects of a service (Terwiel et al., 2017) so this suggests that individual circumstances need to be considered when providing family-centred health care support. In individualised education programs (IEP) in the USA, legislated to support children with disabilities, similar dissatisfaction has been raised by parents that meetings were depersonalised, focused on compliance and paperwork, and decisionmaking was dominated by the professional (Lalvani, 2012; Zeitlin \& Curcic, 2014). It is clear that to truly collaborate with parents and provide individualised care, meaningful interactions with parents are needed that focus on their needs and concerns.

The presence of social support, such as family and friends, can buffer stress (Al-gamal \& Long, 2013; Pousada et al., 2013; Wang et al., 2020), and although caregivers' support levels varied in this study, almost all had valuable support from their partner. Nevertheless, most caregivers in our study also experienced significant stress related to their child's feeding difficulties. One explanation of this apparent disparity could be the effect of chronic parenting stress. The long-term effects of parenting stress can lead to lower perceived emotional support and symptoms of anxiety and depression (Quittner et al., 1990). Literature regarding parental stress and CP is sparse. Glenn et al. (2009) investigated factors predicting parenting stress in mothers of pre-school aged children with CP. High stress items included having a demanding child, role restriction, poor spouse support, and isolation. In the non-CP literature, parenting stress was found to be higher in caregivers of children with a chronic illness and those who had greater parental responsibility for treatment management (Cousino \& Hazen, 2013), such as the caregivers in our study. Interventions have been implemented to reduce parenting stress, such as parental skill development and empowerment (Golfenshtein et al., 2016), however, the long-term effects of the interventions have not been established. This highlights a need to identify and implement systems and resources that may effectively support caregivers and evaluate their effectiveness over time.

In this study, perceived support from health professionals and services varied, so a single solution, such as support groups, would not be adequate to address the needs of all caregivers. Moreover, support from caregivers whose child's disability level was comparable seemed important. Some caregivers expressed a sense of hopelessness and isolation, which they mostly attributed to having no one in a similar situation or understanding what they were going through, so support groups would potentially be useful to these caregivers. Health professionals should be aware of the available support and services available for families and to actively listen to families so appropriate support strategies can be recommended. Caregivers in this study expressed a need to be observed and given immediate feedback on their feeding management, so a home visiting feeding program could be initiated. Home-based programs that include visits and coaching by health professionals have been found effective in supporting parents (Ferre et al., 2017; Kirkpatrick et al., 2016). For parents who live a distance from specialist health services, coaching through internet-based programs (Meadan \& Daczewitz, 2015) could be useful for feeding support. This has become increasingly important during the COVID-19 pandemic 'lockdowns', where feeding support has been provided through web-based communication (Church et al., 2021; Murphy et al., 2021).

The participants in this study had a limited range of cultural diversity as most participants reported their ethnicity as Australian. It is recommended that research on the feeding experiences and support for caregivers of a child with $\mathrm{CP}$ be investigated for different cultural groups, as support experiences may differ. A small number of caregivers were from rural areas. Further exploration around caregivers' feeding and support experiences in low-resource and isolated areas will expand our knowledge to better support this group. In addition, the socioeconomic status of the caregivers was not identified, and although caregivers expressed their perceptions of financial burden, this may have been a factor that could have influenced their responses.

Most of the children in this study were five years or younger, so support provided by school staff was not extensively addressed by the caregivers. In Australia, funding is provided for schools to support children with a disability and can include specialist staff and resources (https://raisingchildren.net.au). Further research into caregiver's experiences of school-based support can expand knowledge in this area that was not fully developed in this study.

\section{Conclusion}

This study provides insight into caregivers' lives and how they are managing difficulties and challenges to meet the unique needs around feeding their child with CP. However, the challenges they faced often led to prolonged worry and stress. The findings highlight that support from professionals needs to be improved to better support parents. Further research on the experiences of caregivers of children with $\mathrm{CP}$ is warranted. Specifically, strategies to support caregivers need to be developed, implemented, and evaluated, especially for caregivers who lack a friend or family support and those who are physically isolated. 
Acknowledgements Thank you to Ms Ayesha Sadozai (AS) who assisted with data collection and ethics application. Many thanks to the mothers who generously gave their time and shared their stories with us.

Author Contributions All authors contributed to the study conception and design. Material preparation, data collection and analysis were performed by C.T., A.C.K. and in part by Ayesha Sadozai. The first full draft of the manuscript was written by C.T. and all authors commented on previous and ongoing versions of the manuscript. All authors read and approved the final manuscript.

Funding This study was partially supported by funding from the Western Sydney University Strategic Initiative funding scheme granted to C.T. No grant number was provided: acceptance approval was sent 16 December 2016. The funding was obtained through C.T.'s employer (Western Sydney University) but this was a competitive grant and the university was not involved in or influenced any aspect of the study project.

\section{Compliance with Ethical Standards}

Conflict of Interest The authors declare no competing interests.

Ethics Approval The study was approved by two Human Research and Ethics' committees (HREC): Western Sydney University HREC [no. H12104] and the Cerebral Palsy Alliance HREC [no. 2017-04-02]. Informed written consent was obtained from all participants.

Publisher's note Springer Nature remains neutral with regard to jurisdictional claims in published maps and institutional affiliations.

\section{References}

Al-gamal, E., \& Long, T. (2013). Psychological distress and perceived support among Jordanian parents living with a child with cerebral palsy: a cross-sectional study. Scandinavian Journal of Caring Sciences, 27, 624-631. https://doi.org/10.1111/j.1471-6712.2012. 01071.x.

Andrew, M. J., Parr, J. R., \& Sullivan, P. B. (2012). Feeding difficulties in children with cerebral palsy. Archives of Disease in Childhood: Education and Practice, 97(6), 222-229. https://doi. org/10.1136/archdischild-2011-300914.

Arvedson, J. C. (2013). Feeding children with cerebral palsy and swallowing difficulties. European Journal of Clinical Nutrition, 67(S2), S9-S12. https://doi.org/10.1038/ejen.2013.224.

Benfer, K. A., Weir, K. A., Bell, K. L., Ware, R. S., Davies, P. S. W., \& Boyd, R. N. (2014). Oropharyngeal dysphagia in preschool children with cerebral palsy: oral phase impairments. Research in Developmental Disabilities, 35(12), 3469-3481. https://doi.org/ 10.1016/j.ridd.2014.08.029.

Benfer, K. A., Weir, K. A., Bell, K. L., Ware, R. S., Davies, P. S., \& Boyd, R. N. (2016). Longitudinal study of oropharyngeal dysphagia in preschool children with cerebral palsy. Archives of Physical Medicine and Rehabilitation, 97(4), 552-560. https:// doi.org/10.1016/j.apmr.2015.11.016.

Blackmore, A. M., Bear, N., Blair, E., Langdon, K., Moshovis, L., Steer, K., \& Wilson, A. C. (2018). Predicting respiratory hospital admissions in young people with cerebral palsy. Archives of Disease in Childhood, 103(12), 1119-1124. https://doi.org/10. 1136/archdischild-2017-314346.
Boel, L., Pernet, K., Toussaint, M., Ides, K., Leemans, G., Haan, J., van Hoorenbeeck, K., \& Verhulst, S. (2019). Respiratory morbidity in children with cerebral palsy: an overview. Developmental Medicine and Child Neurology, 61(6), 646-653. https:// doi.org/10.1111/dmcn.14060.

Bradshaw, C., Atkinson, S., \& Doody, O. (2017). Employing a qualitative description approach in health care research. Global Qualitative Nursing Research, 4, 1-8. https://doi.org/10.1177/ 2333393617742282.

Calis, E. A., Veugelers, R., Sheppard, J. J., Tibboel, D., Evenhuis, H. M., \& Penning, C. (2008). Dysphagia in children with severe generalized cerebral palsy and intellectual disability. Developmental Medicine and Child Neurology, 50(8), 625-630. https:// doi.org/10.1111/j.1469-8749.2008.03047.x.

Carona, C., Crespo, C., \& Canavarro, M. C. (2013). Similarities amid the difference: Caregiving burden and adaptation outcomes in dyads of parents and their children with and without cerebral palsy. Research in Developmental Disabilities, 34(3), 882-893.

Church, P. T., Banihani, R., Watson, J., Chen, W. T. N., Ballantyne, M. \& Asztalos, E. (2021). The E-Nurture project: a hybrid virtual neonatal follow up model for 2021. Children, 8(2), 139. https:// doi.org/10.3390/children8020139.

Cousino, M. K., \& Hazen, R. A. (2013). Parenting stress among caregivers of children with chronic illness: a systematic review. Journal of Pediatric Psychology, 38(8), 809-828. https://doi.org/ 10.1093/jpepsy/jst049.

Dahlseng, M. O., Finbråten, A. K., Júlíusson, P. B., Skranes, J., Andersen, G., \& Vik, T. (2012). Feeding problems, growth and nutritional status in children with cerebral palsy. Acta Paediatrica, 101(1), 92-98. https://doi.org/10.1111/j.1651-2227.2011. 02412.x.

Darrah, J., Wiart, L., Magill-Evans, J., Ray, L., \& Andersen, J. (2012). Are family-centred principles, functional goal setting and transition planning evident in therapy services for children with cerebral palsy? Child: Care, Health \& Development, 38(1), 41-47. https://doi.org/10.1111/j.1365-2214.2010.01160.x.

Erkin, G., Culha, C., Ozel, S., \& Kirbiyik, E. G. (2010). Feeding and gastrointestinal problems in children with cerebral palsy. International Journal of Rehabilitation Research, 33(3), 218-224. https://doi.org/10.1097/MRR.0b013e3283375e10.

Ferre, C. L., Brandão, M., Surana, B., Dew, A. P., Moreau, N. G., \& Gordon, A. M. (2017). Caregiver-directed home-based intensive bimanual training in young children with unilateral spastic cerebral palsy: a randomized trial. Developmental Medicine \& Child Neurology, 59(5), 497-504. https://doi.org/10.1111/ dmen.13330.

Fung, E. B., Samson-Fang, L., Stallings, V. A., Conaway, M., Liptak, G., Henderson, R. C., Worley, G., O'Donnell, M., Calvert, R., Rosenblaum, P., Chumlea, W., \& Stevenson, R. D. (2002). Feeding dysfunction is associated with poor growth and health status in children with cerebral palsy. Journal of the American Dietetic Association, 102(3), 361-373. https://doi.org/10.1016/ s0002-8223(02)90084-2.

Gantasala, S., Sullivan, P. B., \& Thomas, A. G. (2013). Gastrostomy feeding versus oral feeding alone for children with cerebral palsy. The Cochrane Database of Systematic Reviews, 7, CD003943 https://doi.org/10.1002/14651858.CD003943.pub3.

Glenn, S., Cunningham, C., Poole, H., Reeves, D., \& Weindling, M. (2009). Maternal parenting stress and its correlates in families with a young child with cerebral palsy. Child: Care, Health \& Development, 35(1), 71-78.

Golfenshtein, N., Srulovici, E., \& Deatrick, J. A. (2016). Interventions for reducing parenting stress in families with pediatric conditions: an integrative review. Journal of Family Nursing, 22(4), 460-492. https://doi.org/10.1177/1074840716676083. 
Hayles, E., Harvey, D., Plummer, D., \& Jones, A. (2015). Parents' experiences of health care for their children with cerebral palsy. Qualitative Health Research, 25(8), 1139-1154.

Institute for Patient- and Family-Centered Care [IPFCC]. (2016). Advancing the practice of patient- and family-centered care in primary care and other ambulatory settings. https://www.ipfcc. org/resources/GettingStarted-AmbulatoryCare.pdf.

Jeglinsky, I., Autti-Rämö, I., \& Brogren Carlberg, E. (2012). Two sides of the mirror: parents' and service providers' view on the family-centredness of care for children with cerebral palsy. Child: Care, Health \& Development, 38(1), 79-86. https://doi.org/10. 1111/j.1365-2214.2011.01305.x.

King, G., \& Chiarello, L. (2014). Family-centered care for children with cerebral palsy: Conceptual and practical considerations to advance care and practice. Journal of Child Neurology, 29(8), 1046-1054. https://doi.org/10.1177/0883073814533009.

Kirkpatrick, E., Pearse, J., James, P., \& Basu, A. (2016). Effect of parent-delivered action observation therapy on upper limb function in unilateral cerebral palsy: a randomized controlled trial. Developmental Medicine \& Child Neurology, 58(10), 1049-1056. https://doi.org/10.1111/dmcn.13109.

Lalvani, P. (2012). Parents' participation in special education in the contest of implicit educational ideologies and socioeconomic status. Education And Training in Autism and Developmental Disabilities, 47(4), 474-486.

Liamputtong, P. (2020). Qualitative research methods (5th ed.). Oxford University Press.

McDowell, B. C., Duffy, C., \& Parkes, J. (2015). Service use and family-centred care in young people with severe cerebral palsy: a population-based, cross-sectional clinical survey. Disability and Rehabilitation, 37(25), 2324-2329.

Meadan, H., \& Daczewitz, M. E. (2015). Internet-based intervention training for parents of young children with disabilities: a promising service-delivery model. Early Child Development and Care, 185(1), 155-169. https://doi.org/10.1080/03004430.2014. 908866.

Merriam, S., \& Tisdell, E. J. (2016). Qualitative research: A guide to design and implementation (4th ed.). Jossey-Bass Higher and Adult Education Series.

Michael-Asalu, A., Taylor, G., Campbell, H., Lelea, L.-L., \& Kirby, R. S. (2019). Cerebral palsy: diagnosis, epidemiology, genetics, and clinical update. Advances in Pediatrics, 66, 189-208. https://doi. org/10.1016/j.yapd.2019.04.002.

Mobarak, R., Khan, N. Z., Munir, S., Zaman, S. S., \& McConachie, H. (2000). Predictors of stress in mothers of children with cerebral palsy in Bangladesh. Journal of Pediatric Psychology, 25(6), 427-433. https://doi.org/10.1093/jpepsy/25.6.427.

Molinaro, A., Fedrizzi, E., Calza, S., Pagliano, E., Jessica, G., \& Fazzi, E., GIPCI Study Group. (2017). Family-centred care for children and young people with cerebral palsy: results from an Italian multicenter observational study. Child: Care, Health \& Development, 43(4), 588-597. https://doi.org/10.1111/cch. 12449.

Morrow, A. M., Quine, S., Loughlin, E. V. O., \& Craig, J. C. (2008). Different priorities: A comparison of parents' and health professionals' perceptions of quality of life in quadriplegic cerebral palsy. Archives of Disease in Childhood, 93(2), 119-125.

Motion, S., Northstone, K., Emond, A., Stucke, S., \& Golding, J. (2002). Early feeding problems in children with cerebral palsy: weight and neurodevelopmental outcomes. Developmental Medicine and Child Neurology, 44(1), 40-43.

Murphy, A., Pinkerton, L. M., Bruckner, E., \& Risser, H. J. (2021). The impact of the novel coronavirus disease 2019 on therapy service delivery for children with disabilities. The Journal of Pediatrics, 231, 168-177. https://doi.org/10.1016/j.jpeds.2020. 12.060 .
Novak, I., \& Berry, J. (2014). Home program intervention effectiveness evidence. Physical \& Occupational Therapy in Pediatrics, 34(4), 384-389. https://doi.org/10.3109/01942638.2014.964020.

QSR International Pty Ltd. (2018). NVIVO: NVivo qualitative data analysis software (Version 12). https://www.qsrinternational. com/nvivo-qualitative-data-analysis-software/home.

Odding, E., Roebroeck, M. E., \& Stam, H. J. (2006). The epidemiology of cerebral palsy: incidence, impairments and risk factors. Disability \& Rehabilitation, 28(4), 183-191. https://doi.org/ 10.1080/09638280500158422.

Oskoui, M., Coutinho, F., Dykeman, J., Jetté, N., \& Pringsheim, T. (2013). An update on the prevalence of cerebral palsy: a systematic review and meta-analysis. Developmental Medicine \& Child Neurology, 55(6), 509-519. https://doi.org/10.1111/dmen. 12080.

Palisano, R., Rouenbaum, P., Walter, S., Russell, D., Wood, E., \& Galuppi, B. (1997). Development and reliability of a system to classify gross motor function in children with cerebral palsy. Developmental Medicine \& Child Neurology, 39(4), 214-223. https://doi.org/10.1111/j.1469-8749.1997.tb07414.x.

Parkes, J., Caravale, B., Marcelli, M., Franco, F., \& Colver, A. (2011). Parenting stress and children with cerebral palsy: A European cross-sectional survey. Developmental Medicine \& Child Neurology, 53(9), 815-821. https://doi.org/10.1111/j.1469-8749. 2011.04014.x.

Petersen, M., Kedia, S., Davis, P., Newman, L., \& Temple, C. (2006). Eating and feeding are not the same: Caregivers' perceptions of gastrostomy feeding for children with cerebral palsy. Developmental Medicine \& Child Neurology, 48(9), 713-717.

Pfeifer, L. I., Silva, D. B. R., Lopes, P. B., Matsukura, T. S., Santos, J. L. F., \& Pinto, M. P. P. (2014). Social support provided to caregivers of children with cerebral palsy. Child: Care, Health \& Development, 40(3), 363-369. https://doi.org/10.1111/cch.12077.

Pousada, M., Guillamón, N., Hernández-Encuentra, E., Muñoz, E., Redolar, D., Boixadós, M., \& Gómez-Zúñiga, B. (2013). Impact of caring for a child with cerebral palsy on the quality of life of parents: A systematic review of the literature. Journal of Developmental and Physical Disabilities, 25(5), 545-577. https://doi. org/10.1007/s10882-013-9332-6.

Quittner, A. L., Glueckauf, R. L., \& Jackson, D. N. (1990). Chronic parenting stress: Moderating versus mediating effects of social support. Journal of Personality and Social Psychology, 59(6), 1266-1278. https://doi.org/10.1037/0022-3514.59.6.1266.

Reid, A., Imrie, H., Brouwer, E., Clutton, S., Evans, J., Russell, D. \& Bartlett, D. (2011). "If I knew then what I know now": Parents' reflections on raising a child with cerebral palsy. Physical \& Occupational Therapy in Pediatrics, 31(2), 169-183. https://doi. org/10.3109/01942638.2010.540311.

Reyes, F. I., Salemi, J. L., Dongarwar, D., Magazine, C. B., \& Salihu, H. M. (2019). Prevalence, trends, and correlates of malnutrition among hospitalized children with cerebral palsy. Developmental Medicine \& Child Neurology, 61(12), 1432-1438. https://doi.org/ 10.1111/dmcn.14329.

Rosenbaum, P. (2014). Definition and clinical classification. In B. Dan, M. Mayston, N. Paneth, \& L. Rosenbloom (Eds.), Cerebral palsy: Science and clinical practice (pp. 17-26). Mac Keith Press.

Sandelowski, M. (2000). Whatever happened to qualitative description? Research in Nursing \& Health, 23(4), 334-340.

Skok, A., Harvey, D., \& Reddihough, D. (2006). Perceived stress, perceived social support, and wellbeing among mothers of school-aged children with cerebral palsy. Journal of Intellectual \& Developmental Disability, 31(1), 53-57.

Sleigh, G. (2005). Mothers' voice: a qualitative study on feeding children with cerebral palsy. Child: Care, Health and Development, 31(4), 373-83. 
Smith, S. W., Camfield, C., \& Camfield, P. (1999). Living with cerebral palsy and tube feeding: a population-based follow-up study. Journal of Pediatrics, 135(3), 307-310.

Sullivan, P. B., Juszczak, E., Bachlet, A. M. E., Thomas, A. G., Lambert, B., Vernon-Roberts, A., Grant, H. W., Eltumi, M., Alder, N., \& Jenkinson, C. (2004). Impact of gastrostomy tube feeding on the quality of life of carers of children with cerebral palsy. Developmental Medicine \& Child Neurology, 46(12), 796-800. https://doi.org/10.1017/s0012162204001392.

Sullivan, P. B., Lambert, B., Rose, M., Ford-Adams, M., Johnson, A., \& Griffiths, P. (2000). Prevalence and severity of feeding and nutritional problems in children with neurological impairment: Oxford Feeding Study. Developmental Medicine \& Child Neurology, 42 (10), 674-680. https://doi.org/10.1017/S0012162200001249.
Terwiel, M., Alsem, M. W., Siebes, R. C., Bieleman, K., Verhoef, M., \& Ketelaar, M. (2017). Family-centred service: differences in what parents of children with cerebral palsy rate important. Child: Care, Health \& Development, 43(5), 663-669. https://doi.org/10. $1111 /$ cch. 12460

Wang, Y., Huang, Z., \& Kong, F. (2020). Parenting stress and life satisfaction in mothers of children with cerebral palsy: the mediating effect of social support. Journal of Health Psychology, 25(3), 416-425. https://doi.org/10.1177/ 1359105317739100.

Zeitlin, V. M., \& Curcic, S. (2014). Parental voices on individualized education programs: 'Oh, IEP meeting tomorrow? Rum tonight!'. Disability \& Society, 29(3), 373-387. https://doi.org/10.1080/ 09687599.2013 .776493$. 